\title{
65 anos de televisão: o conhecimento do telejornalismo e a função pedagógica
}

\section{5 years of the television: the knowledge of the tele journalism and the pedagogical function}

\section{Alfredo Pereira Vizeu}

Professor Doutor do Programa de Pós-Graduação (PPGCOM) da Universidade Federal de Pernambuco (UFPE). <a.vizeu@yahoo.com.br>

Laerte José Cerqueira da Silva

Doutorando em Comunicação no PPGCOM da Universidade Federal de Pernambuco (UFPE).

<professor.laertecerqueira@gmail.com>

\section{RESUMO}

Neste artigo, discorremos sobre a função pedagógica do Jornalismo e os processos didáticos presentes nos telejornais. Entendemos esses processos como estratégias para produção de um conhecimento de fácil compreensão e referência para a vida em comunidade. Para isso, fizemos uma análise enunciativa de reportagens de economia e política, exibidas no Jornal Nacional, da Rede Globo, entre os dias 23 de dezembro de 2014 e 13 de janeiro de 2015. Percebemos que entre os recursos dessa (re)produção está o diálogo permanente entre elementos textuais, imagéticos, gráficos e sonoros, sustentados pelo rigor do método de apuração. A análise identifica na prática telejornalística procedimentos teóricos importantes para contribuirmos com o fortalecimento dos estudos sobre o jornalismo.

Palavras-chave: Comunicação. Telejornalismo. Função Pedagógica.

\begin{abstract}
In this article, we carry on about the pedagogical function of Journalism and educational processes present in the news. We understand these processes as strategies for producing an easy to understand and reference knowledge to community life. So we developed an enunciative analysis of economic reports and political, displayed in the Jornal Nacional, Rede Globo, between 23 December 2014 and 13 January 2015. We perceived that among the features of this (re)production is the permanent dialogue between textual elements, imagery, graphics and sound, sustained for the accuracy of the investigation method. The analysis identifies in practice of the TV Journalism important theoretical procedures to contribute to the strengthening of journalism studies.
\end{abstract}

Keywords: Communication. TV Journalism. Pedagogical function.

\section{O poder do telejornalismo}

Há 65 anos era criada a televisão e nascia com ela o primeiro telejornal do Brasil: Imagens do Dia. Com o tempo, o telejornalismo logo ocupou a preferência dos brasileiros e é o principal meio de comunicação do País. Noventa e cinco por cento dos brasileiros assistem à TV regulamente e $74 \%$ a veem todos os dias. É o meio de comunicação mais usado pelos brasileiros. A informação é da Pesquisa Brasileira de Mídia 2015 (PMB), da Secretaria de Comunicação Social 
da Presidência da República (Secom, 2015). Foram realizadas 18 mil entrevistas pelo lbope.

O estudo revelou que aumentou a confiança nas notícias. Mas, o que nos chama a atenção neste trabalho éque, apesar de todas as críticas, o telejornalismo continua se mantendo como meio hegemônico de informação jornalística da sociedade. 79\% das pessoas assistem à televisão para se informar. Ou seja, de alguma forma o noticiário televisivo funciona como uma espécie de lugar de referência (Vizeu e Corrêa, 2008) para as pessoas saberem o que está ocorrendo no mundo que as cerca. Um "lugar", para muitos brasileiros, muito semelhante ao da família, dos amigos, da escola, da religião e do consumo. Quando assistimos a um telejornal, em particular, é como se víssemos o mundo, ele está, ele nos vê. Para o bem ou para o mal, o Jornalismo contribui para contextualizar e também pode ajudar na compreensão em torno de sociedades cada vez mais complexas (Melucci, 2001).

É dentro deste contexto que desenvolvemos nosso trabalho. Grosso modo, se o telejornalismo, o Jornalismo, contribui para os homens e as mulheres entenderem um pouco mais o cotidiano em que vivem, pode-se supor que ele é uma forma de conhecimento. A questão é que tipo de conhecimento? Como chegamos a ele no telejornalismo? Que processos o constituem? A discussão sobre o conhecimento do jornalismo não é nova, por isso, apresentaremos os olhares de alguns autores para chegarmos à hipótese que estamos elaborando de conhecimento do desvelamento (Vizeu, 2014).

Um dos primeiros pesquisadores a trabalhar essa perspectiva foi Robert Park (1972). Com base no pensador William James, um dos principais representantes do pragmatismo, movimento filosófico que exerceu profunda influência no pensamento americano durante parte do século XX, existem dois tipos fundamentais de conhecimento: o conhecimento de e o conhecimento acerca de. O autor explica que o conhecimento de é uma espécie de conhecimento que adquirimos no curso dos nossos encontros pessoais e de primeira mão do mundo que nos rodeia. Já o conhecimento acerca de é formal. É o conhecimento que atingiu certo grau de precisão e exatidão, substituindo a realidade concreta por ideias e as coisas por palavras.

Genro (1987), em trabalho fundamental para quem quer pensar o jornalismo como uma forma social de conhecimento, apesar de reconhecer a contribuição de Park, critica seus pressupostos teóricos, afirmando que ele não vai além da função orgânica da notícia e da atividade jornalística. No entender dele, a postura assumida por Parké redutora porque supõe uma espécie de senso 
comum isento das contradições internas, cuja função seria somente reproduzir e reforçar as relações sociais vigentes, integrar os indivíduos na sociedade.

Com base no referencial teórico de Genro, Meditsch (1992) argumenta que o conhecimento do jornalismo é diferente do conhecimento da ciência. Enquanto o primeiro é o modo de conhecimento do mundo explicável, o segundo é o modo de conhecimento do mundo sensível. A Ciência trabalha com hipóteses, enquanto o Jornalismo trabalha com o universo das notícias que diz respeito às aparências do mundo. Ao nível metodológico, isso resulta em diferenças importantes. A hipótese está relacionada como a experimentação controlada. É um corte abstrato na realidade, através do isolamento de variáveis, que permite a obtenção de respostas a um questionamento baseado em conhecimento anterior. A teoria científica expõe uma relação entre fatos e a partir dela surgem novas deduções, através da lógica (Meditsch, 1992).

De acordo com Meditsch (1992), o Jornalismo, por sua vez, não parte de uma hipótese, mas de uma pauta (agenda de assuntos que podem virar notícia). A pauta, diferentemente da hipótese, não surge de um sistema teórico anterior, mas da observação não controlada (do ponto de vista da metodologia científica). Na pauta o isolamento das variáveis é substituído pelo ideal de aprender o fato dos mais diversos pontos de vista. Isso determina o limite da abstração possível no modo de conhecimento do Jornalismo e sua possibilidade de acumulação.

O conhecimento produzido pelojornalismoé de fundamental importância para a sociedade. Ao tratar do tema, Sponholz (2009) propõe um conhecimento híbrido do Jornalismo, que ficaria entre o senso comum e a ciência. Para a autora, o senso comum não se reduz só às ações cotidianas. É uma espécie de conhecimento "naturalizado", determinado fato, certo procedimento, é assim porque sempre foi assim, não há porque questioná-lo.

Entendemos que os conceitos propostos contribuíram e contribuem muito para os estudos e Teorias do Jornalismo, mas, ainda, é preciso avançar mais na compreensão do Telejornalismo como forma de conhecimento. A proposta que esboçamos logo a seguir ainda está dentro de um movimento inicial, mas busca procurar entender algo que é central para o campo jornalístico e que ainda há muito a se investigar: afinal, de qual conhecimento estamos falando quando tratamos do Jornalismo, do telejornalismo em particular?

Para admitirmos que o mundo é uma forma de conhecimento partimos do pressuposto que é possível conhecer. Nesta perspectiva, acreditamos que a realidade é constituída por fatos brutos, que independem das crenças, desejos e necessidades, e cognitividade dos seres humanos e dos fatos institucionais, que dependem de um jeito ou de outro da intervenção humana (Searle, 1997). 
É nesse contexto que é produzido o fato jornalístico e o jornalismo produz o que vamos denominar, provisoriamente, com base nos estudos de Paulo Freire, de o conhecimento do desvelamento, com o objetivo de procurar entender o conhecimento do Jornalismo (Vizeu, 2014, p. 866-870). No entendimento de Freire (1976), é preciso ir mais além do que os simples fatos para compreender a realidade. É a tarefa que diariamente no cotidiano das redações e nas ruas os jornalistas realizam para desvendar os fatos. Freire faz observações como se estivesse dando uma aula para jornalistas.

Freire (1977) argumenta que não acontece uma ruptura porque a curiosidade ingênua, sem deixar de ser curiosidade, continuando a ser curiosidade, se criticiza. Ao se criticizar, tornando-se curiosidade epistemológica, metodicamente "rigorizando-se" na sua aproximação ao objeto, conota seus achados de maior exatidão. A curiosidade metodicamente rigorosa do método cognoscível se torna curiosidade epistemológica, mudando de qualidade, mas não na essência.

É dentro desse quadro que opera o conhecimento do jornalismo. Na produção da notícia, o jornalista trabalha constantemente dentro dessa perspectiva de superação. Não é permitido ao jornalista que seja ingênuo na cobertura dos fatos. A tomada de consciência (Freire, 2003) é o ponto de partida da sua atividade. Como é possível dar conta da cobertura dos acontecimentos, da mediação entre eles e a sociedade, se antes de construir a informação não conheço o objeto? É tomando consciência dele que me dou conta do objeto, que é conhecido por mim.

A eficácia da atividade jornalística e o conhecimento do Jornalismo estão intimamente ligados ao que Freire (1995) colocava como a capacidade de abrir a "alma"da cultura, de aprender a racionalidade da experiência por meio de caminhos múltiplos, deixando-se "molhar, ensopar"das águas culturais e históricas dos indivíduos envolvidos na experiência. É dimensão crítica do conhecimento jornalístico, num imbricamento entre teoria e prática.

Há ainda um longo caminho a percorrer sobre o conhecimento do desvelamento no telejornalismo. No entanto, alguns fenômenos, que apontamos agora, constituem e são importantes para a constituição do conhecimento de desvelamento. Observamos que alguns fenômenos são, na verdade, processos complexos de produção. Vamos listá-los, neste estudo, com ênfase ao processo pedagógico.

Identificamos no Jornalismo cinco processos: atualidade (discurso do presente); objetividade (aproximação da verdade do fato jornalístico); interpelação e audiência interativa (interatividade); leitura (convite à audiência 
aos vazios deixados nos discursos verbais e não verbais); e processos pedagógicos, para os quais nós abrimos espaço agora.

\section{Telejornalismo: a função pedagógica/didática}

Qual é o mundo que o telejornalismo representa a cada edição? Os fragmentos da vida cotidiana, os fatos políticos, econômicos, científicos ou amenidades, resultaram em que tipo de conhecimento? Provavelmente, no mundo possível, como definiu Alsina (2009). Aquele que cabe em alguns segundos, minutos, arrancado e destacado em meio aos vários momentos da realidade, o mundo real, mas que parte de um mundo referenciado, colocado sob a lógica cognoscitiva, única maneira de apresentá-lo como presente e fazêlo ser entendido.

Para Gomis, os meios de comunicação, entre eles, a televisão, oferecemnos um presente social abrangente, aquele que nos é oferecido no meio da jornada, fazendo-nos comunicar. Segundo ele, graças aos meios, nós vivemos em um mundo e sabemos o que está passando em todas as partes. $E$ ainda graças aos meios, percebemos a realidade "não com a fugacidade de um instante e, sim, como um período consistente e objetivado, com possibilidades de perceber e comentar" (Gomis, 1991, p.14).

O que os jornalistas fazem diariamente é "organizar o mundo", procurando torná-lo mais compreensível. Por isso, há uma preocupação pedagógica no jornalismo que se legitima como o lugar de "poder mostrar", de "poder dizer", "interpretar", de"poder analisar". O jornalismo se autorreferencia como um lugar de mediação, de revelação da verdade e orientação de homens e mulheres na contemporaneidade.

Tuchman (1983) afirma que o enquadramento das notícias organiza a realidade cotidiana e é parte importante dessa por causa do caráter público, característica essencial da notícia. Complementa, afirmando que a notícia não só define, redefine, constitui e reconstitui significados sociais; mas, também, define e redefine, constitui e reconstitui maneiras de fazer coisas: os processos existentes e as instituições. E a função pedagógica ocupa um papel central nesse processo. As notícias devem ter a preocupação de contribuir para o entendimento do mundo da vida. Verón (1983) vê o jornalista como um "enunciador pedagógico", que pré-ordena o universo do discurso visando o leitor, que procura orientar, responder-lhe às questões, em suma informar, sempre guardando uma distância do objetivo dele. Essa função pedagógica é trabalhada, diariamente, pelos jornalistas na redação através de uma operação/ 
construção que denominamos de didática (Vizeu, 2005; Vizeu, Correia, 2006). É resultado de uma série de enquadramentos culturais, das práticas sociais, da cultura profissional, dos constrangimentos organizacionais e do campo da linguagem que os jornalistas mobilizam para produzirem notícias.

Vilches (1989) observa que não se pode esquecer que o telejornal estabelece com o espectador (audiência) uma relação pedagógica, pois ensina como se portar diante do texto televisivo, com que atitude comunicativa e em que condições deve aprender as características do gênero. Ou seja, operando de uma forma didática a notícia faz uma mediação entre os diversos campos de conhecimento e o público. Vejamos um exemplo para deixar mais clara essa preocupação didática. Um locutor diz: "Os médicos ficaram surpresos com o resultado do exame que registra a atividade linfocitária de um paciente com AIDS. O exame é feito para medir a capacidade de defesa imunológica de uma pessoa" (Paternostro, 2006).

Ao se referir a um exame médico, que não é conhecido pela maioria da audiência, o editor, de uma maneira geral, vai ter a preocupação, ao redigir o texto para o locutor, de explicar para que serve aquele determinado exame. É uma tentativa de fazer com que a mensagem seja compreendida pelo maior número de pessoas.

O texto jornalístico é um espaço habitado, um universo em movimento: "ler" é pôr em movimento esse universo, aceitando-o ou recusando-o, indo à direita ou à esquerda, investindo mais ou menos esforço, fingindo escutar ou escutando. Os jornalistas, de uma maneira geral, têm uma preocupação "didática"com relação à audiência. Isso é trabalhado desde os tempos da universidade até o dia a dia da redação. No que diz respeito ao mundo acadêmico, o livro de Paternostro, O Texto na TV: Manual de Telejornalismo, adotado pela maioria dos cursos de jornalismo do Brasil, é um exemplo disso. No capítulo que trata do texto coloquial, a autora diz que a tevê tem a obrigação de respeitar o telespectador e transmitir a informação em uma linguagem coloquial e correta. Ela explica que quem assiste ao telejornal só ouve o texto uma vez, por isso deve ser capaz de captá-lo, processá-lo e retê-lo instantaneamente. Não há uma segunda chance.

Se o telespectador se desligar, não há desculpas: o erro foi nosso. Quanto mais as palavras (ou o texto como um todo) forem 'familiares' ao telespectador, maior será o grau de comunicação. As palavras e as estruturas das frases devem estar o mais próximo possível de uma conversa. Devemos usar palavras simples e fortes, elegantes e 
bonitas, apropriadas ao significado e à circunstância da história que queremos contar (Paternostro, 2006, p.78-85).

A autora, experiente profissional da Rede Globo de Televisão, onde trabalhou como editora, editora-chefe de um jornal de Rede e chefe de redação da GloboNews, canal de notícias da tevê paga, hoje na função de assessora da direção da empresa, sabe bem do que está falando. Atualmente ela é a responsável pela Gerência de Desenvolvimento de Jornalistas da Globo. O Manual de Telejornalismo da Rede Globo assume um "ar professoral" ao explicar como o telespectador, a audiência deve ser tratada:

Um dos grandes desafios do telejornalismo é a 'tradução' de informações técnicas, a apresentação de pacotes econômicos, a decifração de termos financeiros etc. Tanto o repórter - na hora de colher as informações - como o redator, na hora de escrever o off, a cabeça da matéria deve ser humilde o suficiente para perguntar, pesquisar e simplificar [...] É preferível sermos tachados de professorais por uma elite de escolarização a não sermos entendidos por uma massa enorme de telespectadores comuns (Manual da Rede Globo de Telejornalismo, 1986, p.23-24).

Dezesseis anos depois, o Novo Manual de Telejornalismo da Rede Globo (2001) não foge muito das recomendações do primeiro na sua preocupação com a audiência. Segundo o manual, toda informação deve ser precisa, cada imagem ou cada palavra escolhida criteriosamente, sob pena de distorcer os fatos e confundir o telespectador:

A nossa honestidade e ética podem ser involuntariamente comprometidas por imprecisões que levem ao telespectador a nos confundir com praticantes de um jornalismo tendencioso e irresponsável [...] (Novo Manual de Telejornalismo da Rede Globo, 2001, no prelo).

\section{Processos didáticos}

Como exemplo desse processo pedagógico e ações didáticas, observamos como o Jornal Nacional, o telejornal mais popular do país e líder de audiência no Brasil, trabalhou na construção de algumas reportagens veiculadas entre os dias 
23 de dezembro de 2014 e 13 de janeiro de 2015, período no qual estavam sendo veiculadas reportagens sobre a reforma ministerial e as mudanças econômicas do governo federal. Reportagens de política e economia, geralmente, sob a responsabilidade de especialistas, que recebem um tratamento especial porque têm na sua natureza termos, expressões e conteúdo de conhecimento específico e precisa de uma "tradução" para chegar a um grande público, um público diverso e heterogêneo, que é imaginado como consumidor desta informação.

Fizemos uma análise enunciativa (Gomes, 2013, p. 86) de vídeos de reportagens que estão disponíveis na internet, mas que foram exibidas originalmente na televisão aberta. Nas matérias, observamos os rastros de sentido que o jornalista deixa no texto e na sua consequente relação com a imagem, para contribuir com a produção de um conhecimento acessível ao telespectador. Assim, acreditamos identificar ações didáticas no que chamamos de processo pedagógico do jornalismo, que se materializa na repetição das formas textuais, na relação com o imagético e com os grafismos.

Em matéria veiculada pelo Jornal Nacional (Figuras 1 e 2), dia 23/12/2014, por exemplo, a presidente Dilma Rousseff anuncia 13 novos nomes que vão compor os ministérios. Na cabeça, parte da reportagem em que o apresentador chama a material, é dito que ela fez o anúncio, mas, segundo o ministro da Justiça, José Eduardo Cardoso, o Ministério Público não poderia fornecer informações, como a presidente queria, para evitar a indicação de políticos investigados na Operação Lava Jato (investiga corrupção na Petrobras). O off, parte da reportagem em que o repórter lê texto escrito por ele, coberto por imagens, começa com a seguinte frase:"A presidente abriu o Palácio da Alvorada para uma festa de confraternização com parlamentares governistas e os atuais ministros" (Jornal Nacional, 2014).

- Figura 1 - Chegada ao Planalto

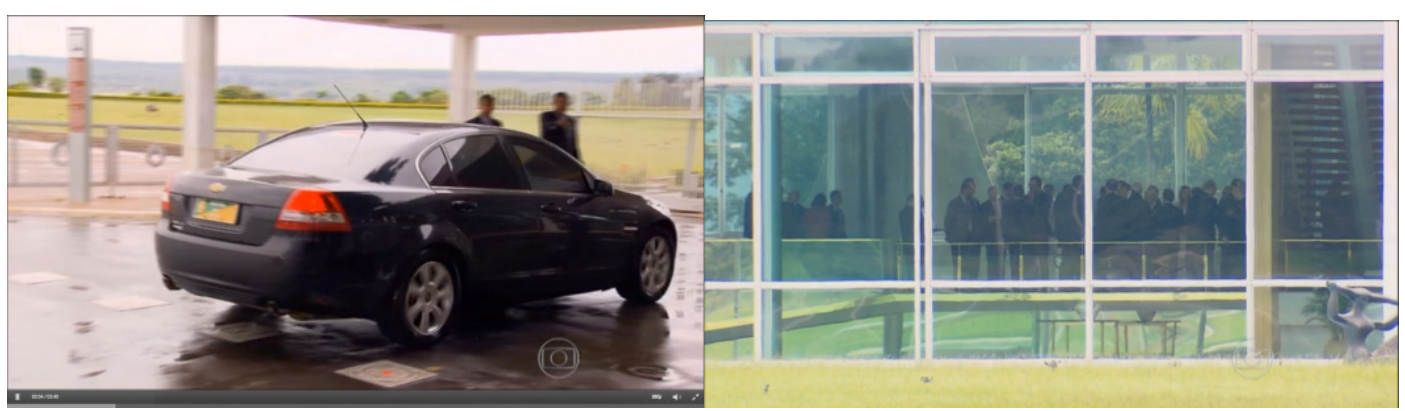

Fonte: REDE GLOBO - reportagens veiculadas no Jornal Nacional 
Esta parte do texto se enquadra no que chamamos de processo didático de ambientação. Ou seja, nessa operação a imagem pode ou não seguir à risca o que está sendo dito, mas o diálogo entre eles é suficiente para fazer com que o telespectador seja introduzido ao ambiente, entenda o clima do momento que a reportagem tenta descrever. Nesse caso, é uma frase que, se retirada da reportagem não afetará o objetivo da matéria, que é anunciar os nomes dos ministros, mas tê-lo ajuda o telespectador entender que mesmo sendo a despedida de alguns ministros, não é um momento de conflito, revolta e sim de confraternização. Neste caso, uma imagem mostra vários carros oficias chegando à residência da presidente, outra de longe, que identifica um grande salão, com várias pessoas reunidas, em pé, aparentemente numa conversa informal. A reportagem continua dizendo que para muitos foi um dia de despedida, já que não vão seguir nos cargos no segundo mandato de Dilma. Na sequência temos: "A definição está sendo feita mesmo sem contar com a colaboração do procurador-geral da República. Nesta segunda-feira, Dilma Rousseff disse que antes de confirmar quem vai para os ministérios iria consultar Rodrigo Janot sobre políticos com envolvimento no esquema de corrupção" (Jornal Nacional, 2014). Nessa parte do texto, temos o que chamamos de processo didático de contextualização. Ao afirmar que a definição dos novos ministros está sendo feita sem ajuda do procurador-geral, o repórter precisa explicar o motivo e, para isso, retoma, por meio do discurso indireto, uma fala dita no dia anterior pela presidente. A imagem, resgatada do dia anterior, ajuda na compreensão porque mostra a presidente no momento que falou a frase resgatada pelo repórter. Sem esse "resgate" de texto imagem, o telespectador teria dificuldade de entender porque que Dilma queria contar com a colaboração de Janot.

Logo na sequência do texto descrito acima, temos uma fala da presidente Dilma. A sonora, como se chama na televisão o recorte feito na entrevista para composição de uma matéria, diz o seguinte: "Eu vou perguntar o seguinte: 'Há alguma coisa contra fulano que me impeça de nomeá-lo?'. Só isso que vou perguntar. Não quero saber o resto, porque ele não pode me dizer". Nesse momento se materializa o que chamamos de processo didático de complementaridade. Ou seja, a fala não só ratifica o que o repórter disse no discurso indireto, mas complementa. Artifício no telejornalismo para ganhar tempo e introduzir a fala de alguém para complementar uma afirmação, esse mecanismo também mantém um ritmo interessante na reportagem porque evita quebras, explicações que dispersem o telespectador e amarra de maneira 
uníssona o texto do repórter e a fala do personagem. Geralmente, esse tipo de mecanismo é operado na ilha de edição, quando na narração do repórter há um ponto de corte que facilite a união, ou quando o texto é feito com a entrevista decupada (fala transcrita). O mesmo mecanismo de complementaridade é usado na sequência, quando com a palavra "mas", o repórter complementa, dialoga mais uma vez com a sonora. Repórter: "Mas o ministro da Justiça, José Eduardo Cardozo, informou que Rodrigo Janot não pode passar nenhuma informação para a presidente". A palavra, que traz o sentido adversativo, revela a contrariedade, introduz a reposta negativa do ministro da Justiça às inquietações e expectativas de Dilma, registradas na própria fala.

Nesse mesmo texto, também identificamos o que chamamos de processo didático de reforço. Vejamos parte do off: "A presidente Dilma Rousseff anunciou que o PMDB vai ganhar mais um ministério. Hoje o partido tem cinco e vai passar a ter seis. Para o Ministério de Minas e Energia, irá o senador Eduardo Braga, atual líder do governo no Senado". Nesse caso, na frase em negrito observamos que é só um reforço do que já foi dito. Se o PMDB vai ganhar mais um ministério e tem cinco, é óbvio que terá seis. Por que, então, a nova frase "vai passar a ter seis"? Nesse tipo de situação, para evitar que o telespectador precise, na instantaneidade do momento, precise fazer conta, mesmo simples. O resultado é revelado de maneira mais evidente possível, mesmo correndo o risco da repetição de ideia, redundância. Em outra parte do off, com a lista de ministros escolhidos, temos: "A presidente Dilma Rousseff ainda anunciou os nomes de outros sete ministros. Para a Controladoria-Geral da União, vai Valdir Simão, de perfil técnico. Ele entra no lugar de Jorge Hage [...]". Nesse caso, destacamos a palavra "ainda" porque, ela funciona como ferramenta de concretização do que chamamos de processo didático que chamamos de pausa/continuidade. Ele é usado, geralmente, quando é precisa fazer uma lista longa de elementos, nomes, objetos. Talvez pareça uma simples palavra no meio do texto, mas no caso da televisão, veículo caracterizado pela facilidade de dispersão, o mecanismo é um espécie de organizador do relato para manter o receptor atento. Introduz uma rápida pausa na lista anterior e abre espaço para apresentar novos elementos. O objetivo é também tornar a descrição mais pedagógica, professoral e facilitar a absorção daqueles nomes ou em outros casos de uma nova ideia. Ainda na produção do texto, observamos outros recursos usados pelos jornalistas para dar um tom professoral quando se apropria do discurso de outro campo do conhecimento. Em reportagem exibida na edição do dia 30 de dezembro de 2014, sobre as novas regras de benefícios previdenciários e trabalhistas, que vão reduzir gastos em quase $\mathrm{R} \$ 20$ bilhões, foi preciso recorrer ao que chamamos de 
processo didático de exemplificação. A ferramenta é usada para fazer com que a informação anterior ao aparecimento do mecanismo seja mais detalhada, com um exemplo mais próximo da realidade do telespectador. É uma tentativa de mostrar como as regras, leis, determinações etc. vão ser aplicadas na realidade cotidiana. Em um dos trechos da reportagem que elenca quais serão as novas normas, o texto diz: "O Tribunal de Contas da União vem identificando irregularidades e falhas nos cadastros de beneficiários como pagamentos indevidos ou em duplicidade e valores incorretos. O próprio governo aponta distorções na concessão desses benefícios. Como por exemplo, a quantidade de viúvas jovens recebendo pensão por morte até o fim da vida. São concedidas quase 50 mil novas pensões por ano a viúvas com menos de 44 anos. (Figura 3). Observamos que para tornar dar mais clareza sobre os pagamentos indevidos e distorções, o jornalista de maneira didática, inclusive com o uso de conectivos linguísticos, a exemplo de "como por exemplo", "por exemplo" ou é o "caso de". $\mathrm{Na}$ mesma reportagem, encontramos outro exemplo. Ao dizer que a partir daquela data o cônjuge, companheiro ou companheira com menos de 44 anos de idade terá o benefício por tempo determinado, com variação de três a 15 anos, dependendo da idade, com diminuição do valor da pensão, os jornalistas que construíram o texto foram em busca de exemplos do cotidiano, que podem ser uma "simulação" (Figura 4) a partir das informações ou até com o uso de uma personagem real que se enquadre a descrição.

- Figura 3 - Tópicos de explicação

Figura 4 - Família simulada

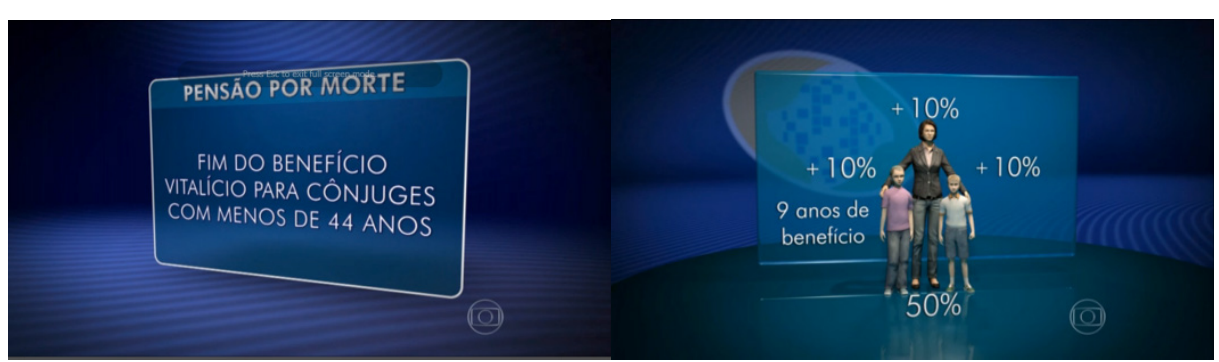

Fonte: REDE GLOBO - reportagens veiculadas no Jornal Nacional

O texto diz: "Por exemplo, uma viúva de 30 anos, com dois filhos menores, vai receber $50 \%$ do valor da pensão. Ela e cada dependente terão direito a mais $10 \%$ do valor do benefício. A pensão será paga a ela por nove anos, de acordo com a faixa etária. Ao fim desse período, ela deixa de receber os $10 \%$. 0 restante continua a ser pago, mas para os filhos". Nesta reportagem, o texto que 
exemplifica é reescrito em formato de tópicos sobre uma arte, com a marca da Previdência Social.

No caso da reportagem veiculada dia 29/12/2014, na qual o governo anunciou o aumento do rigor na concessão de benefícios sociais, foi usado o que chamamos de processo didático de descrição em arte. Agora, fora da operação que é feita na linguagem, observamos um recurso é usado com cada vez com mais frequência em reportagens em que é a quantidade de informações técnicas é muito grande, mas é essencial que elas sejam dadas. Com dificuldade de explicar determinados assuntos, com inevitável inserção de números, prazos e regras, editores dos telejornais recorrem cada vez mais ao departamento de arte para inserir artes animadas ou não, com parte do texto que está sendo descrito pelo repórter. São resumos de ideias e frases, em tópicos, que entram na tela no mesmo momento da narração do repórter (Figura 5). O mecanismo se assemelha a uma leitura acompanhada feita pelo telespectador, que pode auxiliá-lo mais facilmente na compreensão. Visto que ao mesmo tempo visão e audição estão sendo acionados e pode facilitar o entendimento do telespectador.

\section{Figura 5 - Descrição em arte}

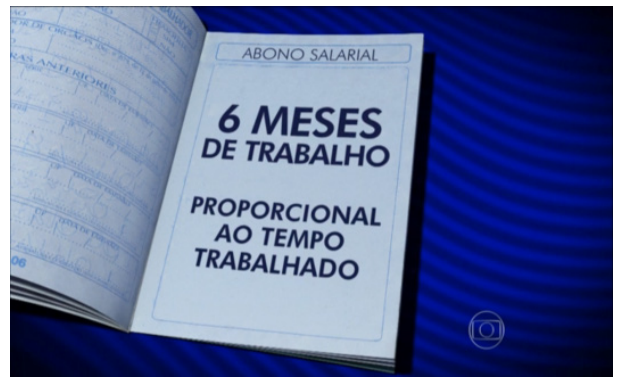

Fonte: REDE GLOBO - reportagemveiculada no Jornal Nacional

O recurso é usado em vários trechos da reportagem, entre eles, esse que diz que "O seguro-desemprego só será pago após um ano e meio seguido de trabalho e não mais após seis meses. Na segunda solicitação, a exigência de tempo trabalhado cai para 12 meses e na terceira, seis meses". Também foi usado o mecanismo, mas com outra arte, ou base, no momento em que a repórter diz como um dependente recebe a pensão por morte.

Na mesma linha de operação didática na edição, aparece o mecanismo de transcrição de fala. Foi o que aconteceu na notícia veiculada na edição do dia 13/01/2015, quando o ministro da Fazenda, Joaquim Levy, fez declarações sobre os repasses que o Tesouro Nacional não fará às distribuidoras de energia. 
As declarações foram dadas sem câmeras a um grupo de jornalistas. Mas como a informação era considerada importante pelo telejornal, a falta de imagens em movimento ou entrevista em vídeo não impediu a transformação do que foi dito em conhecimento para o público. A fala do ministro foi transcrita para uma tela com uma foto dele.

\section{- Figura 6 - Fala de ministro}

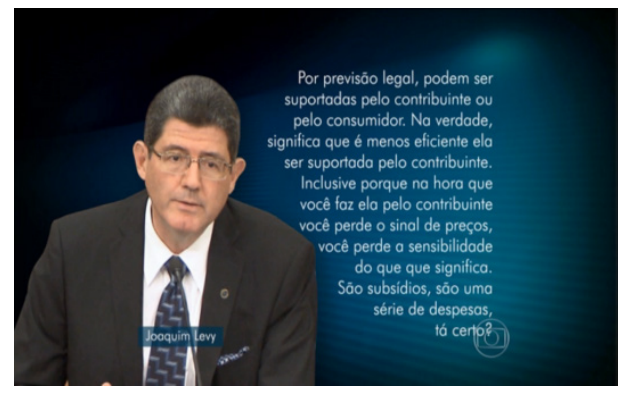

Fonte: Rede Globo - reportagem veiculada no Jornal Nacional

Ao mesmo tempo em que ele falava, o texto era inserido na tela, como se estivesse sendo escrito naquele momento. Sem imagens em movimento, toda a atenção se voltou para a informação dita por ele, que, naquele caso era também de conteúdo denso. O ministro disse que o Tesouro Nacional não vai mais fazer repasses às distribuidoras de energia este ano. Ele avaliou que para o equilíbrio das contas públicas é melhor que os custos extras fiquem com o consumidor, sem a necessidade, por exemplo, de aumentar impostos.

\section{Indo ao Off}

Nas reportagens analisadas, vimos como os processos didáticos se materializam no texto das reportagens e, um pouco, da sua formação na relação com imagem e recursos gráficos. Por trás do aparecimento dessas ferramentas de construção da realidade e da produção de conhecimento para o telespectador, supomos que há um desejo/necessidade dos jornalistas de fazer com que o que é dito seja entendido claramente, sem ruídos e num fluxo contínuo. Na observação apresentada, elencamos e iniciamos uma conceituação dos processos didáticos de ambientação, contextualização, complementaridade, pausa/continuidade, exemplificação e descrição em arte. Acreditamos que há bem 
mais, como o de argumentação, explicação e comparação. Será um caminho e uma busca da nossa pesquisa.

Há muito a fazer para entender, ainda no processo de construção, e não apenas com o produto pronto, como se dá o aparecimento desses processos, que dão força à nossa hipótese de que o jornalismo está cada vez mais didático na resignificação, buscando se aproximar da linguagem falada, da coloquial, com a utilização dos vários tipos recursos gráficos, visuais ou por meio do diálogo de todos esses materializadores das mensagens telejornalísticas. O telejornalismo consegue esse feito de mexer com as pessoas, completando espaços vazios de suas consciências de mundo, reformando conceitos experimentados e ouvidos, desconstruindo e remexendo o baú de nossas lembranças de vida, porque coloca diante de nós questionamentos sobre nossas crenças e verdades naturalizadas, ou seja, nos coloca diante de um conhecimento. Acostado na conclusão de Ekström (2002), o jornalismo é, em suas várias formas, claramente, a mais influente instituição produtora de conhecimento do nosso tempo.

Representações da realidade são produzidas e publicadas dia após dia , com a penetração incomparável. Pessoas obtém conhecimento do mundo fora de sua experiência imediata em grande parte vinda da mídia de massa, onde o conteúdo jornalístico predomina .formas jornalísticas de representar a realidade, os modelos de jornalistas e modus operandi também influenciam outras instituições sociais (Ekström, 2002, p. 2, tradução nossa). ${ }^{1}$

Como lugar de referência e segurança na vida de muitas pessoas, o telejornalismo é procurado para, e dele também se exige, a entrega, de maneira fácil e acessível, o "conteúdo" produzido em várias áreas, campos de conhecimento, em vários mundos. Estudar como os seus agentes, os jornalistas, caminham cada vez mais para o didatismo na construção da mensagem nos permite entender mais sobre essa prática social, institucionalizada, coletiva e que precisa cada vez mais de bases teóricas para fortalecermos a tese que jornalismo não se faz apenas com intuição e senso comum, mas contribui para

1 Renderings of reality are produced and published day in and day out, with unparalleled penetration. People obtain knowledge of the world outside their immediate experience largely from mass media, wherejournalistic content predominates. Journalistic ways of depicting reality, journalists'modelsandmodusoperandialsoinfluenceothersocialinstitutions(Ekström,2002,p.2). 
o homem compreender o mundo. As pesquisas que estamos desenvolvendo procuram mostrar que o telejornalismo pode contribuir de uma forma didática para o aperfeiçoamento democrático. Temos claro que ela hoje reforça fortemente o status quo, mas nada impede que, através dos estudos que estamos desenvolvendo, dos estudos de outros pesquisadores e dos movimentos sociais, possamos contribuir de alguma forma para a mudança deste quadro.

\section{Referências}

ALSINA, Miguel. A construção da notícia. Petrópolis: Vozes, 2009.

EKSTRÖM, Mats. Epistemologies of TV journalism. A theoretical framework. London: Sage Publications, 2002.

FREIRE, Paulo. Cartas a Cristina. Bauru: Unesp, 2003.

Educação na cidade.2. ed. São Paulo: Cortez, 1995.

Pedagogia da autonomia. 4. ed. Rio de Janeiro: Paz e Terra, 1997.

A mensagem de Paulo Freire: textos de Paulo Freire selecionados pelo NODEP. São Paulo: Nova Crítica, 1977.

Ação cultural para a liberdade e outros escritos. Rio de Janeiro: Paz e Terra, 1976.

GENRO FILHO, Adelmo. O segredo da pirâmide. Porto Alegre: Tchê, 1987.

GOMES, Romeu. Análise e interpretação de dados de pesquisa qualitativa. In:

MINAYO, Maria Cecília; DESLANDS, Suely F. Pesquisa Social: Teoria, método e criatividade. Petrópolis, RJ: Vozes, 2013.

GOMIS, Lorenzo. Teoria del periodismo . cómo se forma el presente. Barcelona: Paidós, 1991.

MEDITSCH, Eduardo. O conhecimento do jornalismo. Florianópolis: Ed. UFSC,1992.

MELUCCl, Alberto. A invenção do presente: movimento sociais nas sociedades complexas. Petrópolis: Vozes, 2001.

PARK, Robert. A notícia como forma de conhecimento. In: STEINBERG, Charles. Meios de comunicação de massa. São Paulo: Cultrix, 1972. 
PATERNOSTRO. Vera Íris. O texto na TV. 2. ed. Rio de Janeiro: Editoral Elsevier, 2006.

REDE GLOBO. Jornal Nacional: Dilma Rousseff anuncia novos ministros. Disponível em: <http://g1.globo.com/jornal-nacional/noticia/2014/12/dilma- rousseffanuncia-os-13-nomes-que-vao-compor-o-novo-ministerio.html> Acesso em: 25 fev. 2015.

Jornal Nacional: Novas regras de benefícios reduzem gastos. Disponível em: <http://g1.globo.com/jornal- nacional/noticia/2014/12/novas-regra-debeneficios-vai-reduzir-gastos-em-quase-r-20-bilhoes.html> Acesso em: 25 fev. 2015.

Jornal Nacional: Governo anuncia aumento do rigor na concessãode benefícios sociais. Disponível em: <http://g1.globo.com/jornal-nacional/ noticia/2014/12/governo-anuncia-aumento-do-rigor-na-concessao-debeneficios-sociais.html> Acesso em: 25 fev. 2015.

. Jornal Nacional: Tesouro Nacional não fará repasses às distribuidoras de energia. Disponível em: <http://g1.globo.com/jornal-nacional/noticia/2015/01/ tesouro-nacional-nao-fara-repasses-distribuidoras-de-energia-diz-ministro.

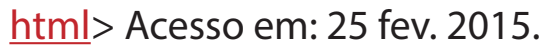

SEARLE, John. La construcción de la realidad social. Barcelona: Paidós, 1997.

SPONHOLZ, Liriam. Jornalismo, conhecimento e objetividade: para além doespelho e das construções. Florianópolis: Insular, 2009.

TUCHMAN, Gaye. La producción de la noticia: estúdio sobre la construcción de la realidad. Barcelona: Gilli, 1983.

VILCHES, Lorenzo. Manipulación de lainformación televisiva. Barcelona: Paidós,1989.

VIZEU, Alfredo. Jornalismo e Paulo Freire: o conhecimento do desvelamento. Revista Famecos, Porto Alegre, v. 21, n. 3, p. 860-877, set. / dez. 2014.

O telejornalismo como lugar de referência e a função pedagógica. Revista Famecos, Porto Alegre, n. 40, set. /dez. 2009.

. A construção do real no telejornalismo: do lugar de segurança ao lugar de referência. In: A sociedade do telejornalismo. Petrópolis: Vozes, 2008.

O lado oculto do telejornalismo. Florianópolis: Calandra, 2005.

VIZEU, Alfredo Eurico ; CORREIA, João Carlos. A construção do real no telejornalismo: do lugar de segurança ao lugar de referência. In: SBPJor 2006, Porto Alegre. Anais... Porto Alegre: 2006. 
Recebido em: 8/12/2015

Aceito em: 21/12/2015

Endereço dos autores:

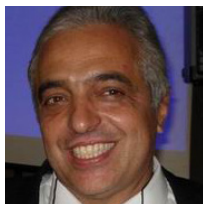

Alfredo Pereira Vizeu <a.vizeu@yahoo.com.br>

http://lattes.cnpq.br/9544888901677710

Programa de Pós-Graduação (PPGCOM) da Universidade Federal de Pernambuco (UFPE).

Avenida Professor Moraes Rego, $\mathrm{s} / \mathrm{n}^{\circ}$ - Cidade Universitária

50670-901 - Recife - Pernambuco - Brasil

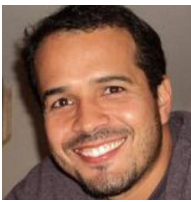

Laerte José Cerqueira da Silva <professor.laertecerqueira@gmail.com>

http://lattes.cnpq.br/9914202333943079

Programa de Pós-Graduação (PPGCOM) da Universidade Federal de Pernambuco (UFPE).

Avenida Professor Moraes Rego, $\mathrm{s} / \mathrm{n}^{\circ}$ - Cidade Universitária

50670-901 - Recife - Pernambuco - Brasil 